\title{
Respuesta de tubérculos comerciales de ñame (Dioscorea spp.) en el momento de la cosecha y almacenamiento poscosecha.
}

\author{
Misterbino Borges García ${ }^{1}$, Yoenia Sánchez Rodríguez ${ }^{2}$ \& Diana María Reyes Avalos ${ }^{3}$ \\ ${ }^{1}$ Identificación ORCID 0000-0002-2052-7294, Centro de Estudios de Biotecnología Vegetal. Facultad de \\ Ciencias Agropecuarias. Universidad de Granma. Carretera Bayamo-Manzanillo Km 17, Apdo 21, Bayamo \\ 85 100, Granma, Cuba. Autor para correspondencia: mborgesg@udg.co.cu. \\ ${ }^{2}$ Identificación ORCID 0000-0002-9572-1024, Centro de Estudios de Biotecnología Vegetal. Facultad de \\ Ciencias Agropecuarias. Universidad de Granma. Carretera Bayamo-Manzanillo Km 17, Apdo 21, Bayamo \\ 85 100, Granma, Cuba. \\ ${ }^{3}$ Identificación ORCID 0000-0003-2305-387. Centro Universitario Municipal Jiguaní. Universidad de \\ Granma., Granma, Cuba.
}

\section{Resumen}

La investigación tuvo como objetivo reducir las pérdidas de tubérculos comerciales de ñame (Dioscorea spp.) mediante un manejo adecuado de la misma durante su cosecha y almacenamiento poscosecha. Se evaluó la incidencia de las principales plagas y enfermedades de tubérculos comerciales de ñame (Dioscorea spp.) durante el momento de la cosecha y su respuesta durante su almacenamiento poscosecha a temperatura ambiente con luz solar indirecta en un local limpio y ventilado contenido dentro de sacos de aspillera. Al cabo de 0,30 y 60 días de almacenamiento se determinó los indicadores morfológicos y agronómicos. A través del método de encuesta se analizaron organolépticamente tubérculos comerciales de ñame (Dioscorea spp.) a 0 y 60 días de almacenamiento. Los resultados obtenidos demostraron como principales enfermedades de tubérculos comerciales de ñame durante el momento de cosecha a Botryodiplodia theobromae, Penicillium spp. y Aspergillus flavus, Link. Se determinó para todos los clones evaluados que a medida que pasa el tiempo de almacenamiento hasta 60 días disminuye el porcentaje de masa fresca de tubérculo y aumenta el de masa seca. Se logró el almacenamiento satisfactorio de los tubérculos comerciales de ñame de $D$. alata de los clones Criollo, Chino Blanco, Caballo, Caraqueño y de D. esculenta clon Papa en sacos de aspillera hasta 60 días en un local ventilado, limpio y con luz solar indirecta a temperatura ambiente. Las pruebas organolépticas evidenciaron que el clon Chino Blanco fue el más aceptado por los panelistas. Finalmente se elaboró un plan de medidas para el manejo de tubérculos de Dioscorea spp. durante su cosecha y almacenamiento poscosecha.

Palabras claves: agricultura sostenible, enfermedades, plagas, pruebas organolépticas

\section{Commercial tubers response of yam (Dioscorea spp.) in the harvest and postharvest crop}

Abstract

The investigation had as objective to reduce the losses of commercial tubers of yam (Dioscorea spp.) by means of an appropriate gestion during harvest and postharvest crop was carried out. The incidence of the main pest and disease of commercial tubers of yam (Dioscorea spp.) during the moment of the harvest crop and its answer during postharvest storage to ambient temperature with indirect solar light in a local clean and ventilated content inside loophole sacks was evaluated. After 0,30 and 60 days of postharvest storage morphological and agronomic indicators were determined. Through the survey method organoleptic test of commercial tubers of yam (Dioscorea spp.) to 0 and 60 days of storage was analyzed. The obtained results demonstrated as main diseases of commercial tubers of yam during the harvest crop moment to Botryodiplodia theobromae, Penicillium spp. and Aspergillus flavus Link. For all the evaluated clones in measure the spends time of storage up to 60 days it diminishes the percentage of fresh mass of tuber and that of dry mass increases. The satisfactory storage of the commercial tubers of yam of $D$. alata clones Creole, Chinese White, Horse, Caraqueño and D. esculenta clone Potato in loophole sacks up to 60 days in a ventilated local, clean and with indirect solar light to ambient temperature. The organoleptic tests evidenced 
the Chinese White was the more accepted by the panelists. Finally a plan of measures for the gestion of tubers of Dioscorea spp. during harvest and postharvest crop was elaborated.

Key words: sustainable agriculture, disease, pest, organoleptic tests

\section{Introducción}

El cultivo del ñame (Dioscorea spp.) es un tubérculo plantado por los pequeños productores en el trópico (Andres et al., 2017). Posee un alto valor alimenticio (Akinrinola y Adeyemo, 2018; Raphiou et al., 2019) y una fuente de energía significativa en la dieta humana (Quainoo et al., 2015). Posee más de 600 especies, pero solamente seis poseen importancia alimenticia y económica a nivel mundial (Abasimi, 2018).

El ñame es un tubérculo considerado sustituto de la papa y la yuca, y su consumo al igual que su producción se da principalmente en países africanos, islas de las Antillas, países de Oceanía y en el continente americano en países como Colombia, Brasil, Venezuela, República Dominicana Jamaica, Costa rica, Puerto Rico, Panamá y Cuba. Aunque tradicionalmente el ñame se ha usado para la alimentación humana también se han encontrado muchos usos en la industria como la cosmética, la farmacéutica, la de plásticos y en la agroindustria, con el proceso de transformación del ñame en harinas y almidones (Ávila, 2013).

Para los pequeños productores, la producción de ñame constituye una importante fuente de alimentos y de ingresos, y también juega un rol vital en su vida sociocultural (Iddi et al.,2018). Es un cultivo tradicional altamente nutritivo que forma parte de los cultivos huérfanos que la Organización de las Naciones Unidas para la Agricultura y la Alimentación (FAO) promueve para luchar contra el hambre en el mundo (FAO, 2016).

Generalmente la cosecha se realiza entre los nueve y diez meses después de la siembra. El ñame está para cosechar cuando las hojas se tornan amarillas y marchitas y los tubérculos presentan su parte distal de color café. El trabajo debe ser cuidadoso y lento para evitar el daño a los tubérculos. Inicialmente se eliminan los tutores del campo, se chapea los lomillos para favorecer la cosecha. Luego con la ayuda de un cosechador halado por un tractor se realiza la cosecha y recolección del ñame, normalmente se hace en sacos con un peso promedio de 20 a $25 \mathrm{~kg}$, sin embargo este transporte no es el más adecuado ya que causa daños al tubérculo. Una vez seleccionado los tubérculos de acuerdo con las exigencias de la planta empacadora, se traslada a la planta para su lavado, una preselección y secado y colocado en el patio de la planta para ser luego empacados en papel periódico en forma individual y una vez completada la caja, son transportados en paletas para ser llevados finalmente al contenedor. Por lo general, los ñames se exportan frescos o se consumen a nivel nacional también frescos.

Los tubérculos que se almacenan para semilla se colocan en cajas de madera (ejemplo: 1 x 0,4 m y $10 \mathrm{~cm}$ de alto), con fondo de cedazo o con un enrejado de reglilla o caña, a fin de que se mantengan secas y sanas, en una bodega ventilada, seca y limpia (Quiros et al., 2007).

La etapa de poscosecha empieza con la cosecha del ñame en el campo y termina en la cocina del consumidor, lo que para efectos de los investigadores abarca factores como las temperaturas de almacenamiento y transporte, el empaque y manejo del producto. Costa Rica es el segundo exportador de ñame más importante a nivel mundial y en 2014 le generó al país un ingreso de \$14,7 millones (UCR, 2016).

Numerosas plagas y enfermedades del ñame son mantenidas de una estación a otra mediante la utilización de material infectado. El desarrollo de un sistema para generar material sano elimina este ciclo de enfermedad y reduce las perdidas en campo y durante el almacenamiento poscosecha (Claudius-Cole et al., 2017).

Ha habido regulaciones para desarrollar el sector de poscosecha de la agricultura debido a las pérdidas inherentes en la producción de cultivos como el ñame. El gobierno de Nigeria ha puesto recientemente en sus prioridades la política de exportación de ñame para reducir las pérdidas de poscosecha y mejorar el ingreso de los productores (Ayado, 2017). Las perdidas poscosecha ha recibido la atención en muchos países para asegurar la seguridad alimentaria global, particularmente en los países en vías de desarrollo (Ansah y Tetth, 2016).

Las causas de pérdidas de almacenamiento de ñames incluyen la brotación, transpiración, respiración, putrefacción debido a la contaminación por bacterias, y al ataque por insectos, nematodos y roedores. La brotación, la transpiración y la respiración son actividades fisiológicas que dependen del ambiente de almacenamiento (principalmente la temperatura y la humedad relativa). Estos cambios fisiológicos afectan la composición interna del tubérculo y dan como resultado la destrucción del material vegetal y mala calidad nutritiva. Las pérdidas de almacenamiento del ñame reportadas son de 10-15\% después de los primeros tres meses y pueden acercarse al 50\% después de seis meses (Adejo, 2017). Sin embargo, en Cuba la literatura 
revisada hasta la fecha no se informan investigaciones relacionadas con las pérdidas de tubérculos comerciales de ñame (Dioscorea spp.) durante la cosecha y su almacenamiento postcosecha. Por ello, la investigación estuvo encaminada a reducir las pérdidas de tubérculos comerciales de ñame (Dioscorea spp.) mediante un manejo adecuado de la misma durante su cosecha y almacenamiento poscosecha.

\section{Materiales y métodos}

La investigación se realizó en el Centro de Estudios de Biotecnología Vegetal (CEBVEG) de la Universidad de Granma, ubicado en el municipio Bayamo, provincia de Granma, Cuba.

\section{Material vegetal}

Se utilizaron tubérculos comerciales de ñame (Dioscorea spp.) procedentes del banco de semilla categorizada del CEBVEG (Tabla 1) cosechados a los 9 meses. La cosecha se efectuó de forma manual a los nueve meses de efectuada la plantación usando pico, coa y pala para evitar daños en los tubérculos cosechados; se utilizaron tubérculos los cuales fueron envasados en sacos aspillera y colgados a temperatura ambiente en un local ventilado con iluminación solar indirecta durante su almacenamiento.

Tabla 1. Tubérculos comerciales de name (Dioscorea spp.) cosechados a los 9 meses procedentes del banco de semilla categorizada del CEBVEG.

\begin{tabular}{ll}
\hline Especie & Clon \\
\hline D. alata & Criollo blanco \\
D. alata & Caballo \\
D. alata & Caraqueño \\
D. alata & Chino blanco \\
D. esculenta & Papa \\
\hline
\end{tabular}

\section{Evaluación de la incidencia de las principales plagas de tubérculos comerciales de name durante el momento de la cosecha}

El experimento tuvo como objetivo evaluar las pérdidas durante el momento de la cosecha de tubérculos comerciales de ñame (Dioscorea spp.).

Se utilizó un diseño experimental completamente aleatorizado. Los tratamientos consistieron en el uso de distintos clones de Dioscorea spp. (Tabla 2). De una población de 100 tubérculos comerciales por tratamiento, se tomaron aleatoriamente 30 tubérculos con tres repeticiones.

Tabla 2. Tratamientos obtenidos durante el momento de la cosecha de tubérculos comerciales de name (Dioscorea spp.) procedentes del banco de semilla categorizada del CEBVEG.

\begin{tabular}{cl}
\hline Tratamientos & \multicolumn{1}{c}{ Clon } \\
\hline 1 & D.alata $($ Criollo blanco) \\
2 & D.alata (Caballo) \\
3 & D.alata $($ Caraqueño) \\
4 & D.alata $($ Chino blanco) \\
5 & D.esculenta $($ Papa $)$
\end{tabular}

Se evaluó en el momento de la cosecha:

Porcentaje de pérdidas: daños mecánicos, plagas y enfermedades 
Identificación de las principales plagas según el Instructivo Técnico del Cultivo del Ñame (MINAG, 2008).

\section{Identificación de los microorganismos patógenos}

Para llevar a cabo la identificación de los patógenos se procedió según los Protocolos Normativos Operacionales de inspección fitosanitaria de plantas (FAO, 2011) adaptados a las condiciones del laboratorio.

Se les realizó un corte a los tubérculos visiblemente afectados por hongos, que comprendían tanto el síntoma como áreas no afectadas próximas a estos. Estos fragmentos de tejido fueron montados en cámara húmeda en condiciones de asepsia durante 24 horas. Se tomaron muestras del micelio germinado y se observó al microscopio óptico para identificar el agente causal de los síntomas. Los resultados fueron comparados con la clave del CMI (1976) para corroborar los resultados.

\section{Respuesta de tubérculos comerciales de ñame (Dioscorea spp.) durante su almacenamiento postcosecha a temperatura ambiente a temperatura ambiente con luz solar indirecta en un local limpio y ventilado.}

El experimento tuvo como objetivo evaluar la respuesta de tubérculos comerciales de ñame (Dioscorea spp.) durante su almacenamiento postcosecha hasta 60 días.

Se utilizó un diseño experimental completamente aleatorizado. Los tratamientos consistieron en el uso de tres momentos de almacenamiento (0, 30 y 60 días) en distintos clones de Dioscorea spp. (Tabla 3). De una población de 100 tubérculos comerciales por tratamiento, se tomaron aleatoriamente 30 tubérculos con tres repeticiones.

Tabla 3. Tratamientos obtenidos durante el almacenamiento a 0,30 y 60 días poscosecha de tubérculos comerciales de ñame (Dioscorea spp.) a temperatura ambiente con luz solar indirecta en un local limpio y ventilado.

\begin{tabular}{llllll}
\hline Tratamientos & Clon & Clon & Clon & Clon & Clon \\
\hline 0 días & Criollo Blanco & Caballo & Caraqueño & Chino Blanco & Papa \\
30 días & Criollo Blanco & Caballo & Caraqueño & Chino Blanco & Papa \\
60 días & Criollo Blanco & Caballo & Caraqueño & Chino Blanco & Papa \\
\hline
\end{tabular}

Los valores registrados de las variables climáticas durante el experimento fueron: temperatura, $30 \pm 2^{\circ} \mathrm{C}$; humedad relativa, $70-80 \%$ y fotoperiodo de $12-14$ horas luz.

\section{Evaluaciones}

Al cabo de 0,30 y 60 días de almacenamiento se determinaron los siguientes indicadores.

Indicadores morfológicos

Color y forma

Porcentaje de brotación

Diámetro del brote $(\mathrm{cm})$ : a los 30 y 60 días se efectuó la medición del diámetro del brote con un pie de rey.

Longitud del brote (cm): a los 30 y 60 días se efectuó la medición de la longitud del brote con una regla graduada.

\section{Indicadores agronómicos}

Porcentaje de pérdidas: daños mecánicos, plagas y enfermedades cosecha y poscosecha.

Masa fresca de tubérculo $(\mathrm{kg})$ : utilizando una balanza técnica se determinó la masa fresca del tubérculo.

Porcentaje de masa seca: se determinó por el método gravimétrico sometiendo $10 \mathrm{~g}$ de tubérculo a $70{ }^{\circ} \mathrm{C}$ en estufa durante 72 horas hasta masa constante, pesados en una balanza eléctrica digital monoplato (modelo 11-DO629) con precisión de $0.3 \mathrm{mg}$. 
Identificación de las principales plagas y enfermedades según el Instructivo Técnico del Cultivo del Name (MINAG, 2008) y Guía para la regeneración de germoplasma de ñame (Dumet y Ogunsola, 2008).

\section{Pruebas organolépticas}

El análisis organoléptico de tubérculos comerciales de ñame (Dioscorea spp.) se realizó a través del método de encuesta atendiendo a los siguientes criterios una vez degustado al azar los diferentes platos:

Por favor marque su criterio

Plato X

Sabor:

Aspecto:

Excelente

Bueno

Bueno

Regular Regular

Semidura Blanda

Textura:

Excelente

Siempre

A veces

Malo

Malo

Deseo volverlo a consumir: Siempre

Clave (Se seleccionó al azar el clon de ñame correspondiente a cada plato)

Plato 1. Clon Criollo

Plato 2. Clon Caballo

Plato 3. Clon Caraqueño

Plato 4. Clon Chino blanco

Plato 5. Clon Papa

\section{Prevención de pérdidas mediante el manejo de tubérculos comerciales de Dioscorea spp. durante su cosecha y almacenamiento poscosecha}

Se elaboró un plan de medidas para la prevención de pérdidas mediante el manejo de tubérculos comerciales de Dioscorea spp. durante su cosecha y almacenamiento poscosecha a partir de los mejores resultados obtenidos en los experimentos anteriores.

\section{Análisis estadístico}

Se utilizó un análisis de varianza de clasificación simple con prueba de comparación múltiple de medias de Tukey al 5\% de probabilidad del error. Para comprobar la normalidad de los datos se utilizó la prueba de Kolmogorov - Smirnov y para la homogeneidad de varianzas la prueba de Barttlet. Todos los análisis estadísticos se realizaron con el programa Statistica para WINDOWS, versión 10.0 (StatSoft, 2011). 


\section{Resultados y discusión}

\section{Respuesta de tubérculos comerciales de ñame (Dioscorea spp.) en el momento de la cosecha}

\section{Pérdidas en el momento de la cosecha}

Se encontró que en el momento de la cosecha se produjeron pérdidas (Tabla 4) en un rango de 14 a $17 \%$ debido a los daños mecánicos de los tubérculos durante la cosecha, derivados de cortes y magulladuras durante el arrancado, amontonamiento, recogida y transporte. Resultados similares alcanzados por Adejo (2017) demostró que las principales pérdidas desde la cosecha hasta los primeros 90 días de almacenaje oscilaron entre un 10 a 15\%, causadas por factores tales como plagas, enfermedades de hongos y bacterias, pobre manejo y logística, facilidades de almacenaje inadecuadas y daños mecánicos.

Tabla 4. Porcentaje de pérdidas por daños mecánicos obtenidos durante el momento de la cosecha de tubérculos comerciales de ñame (Dioscorea spp.)

\begin{tabular}{lc}
\hline \multicolumn{1}{c}{ Tratamientos } & $\begin{array}{c}\text { Porcentaje de pérdidas por daños } \\
\text { mecánicos }(\%)\end{array}$ \\
\hline D. alata (Criollo blanco) & 15 \\
D. alata (Caballo) & 14 \\
D. alata (Caraqueño) & 16 \\
D. alata (Chino blanco) & 17 \\
D. esculenta (Papa) & 14 \\
\hline EE & 0.43 \\
\hline
\end{tabular}

EE, error estándar.

Por otro lado Coursey (1967) señaló que a diferencia de los cereales, todas las plantas tropicales de raíces o de tubérculos forman parte de los productos alimentarios frágiles y perecederos. La cosecha es delicada y debe ser hecha con cuidado, porque condiciona todas las operaciones subsiguientes, en particular, cualquier acción para prevenir los daños o las pérdidas.

No se identificaron bacterias, sin embargo se logró identificar los hongos Botryodiplodia theobromae y Penicillium spp. (Tabla 5, Figura 1) en los clones Papa y Caballo, a partir de pudrición seca presente en los mismos. Mientras que en los clones Criollo y Caraqueño, se encontraron hongos del tipo Penicillium spp. y Aspergillus flavus, Link. Los resultados fueron comparados con la clave del CMI (1976) para corroborar los resultados.

Esta presencia de enfermedades se debe principalmente a los daños mecánicos ocurridos durante la cosecha, ya que estos hongos son capaces de penetrar a través de la epidermis dañada y de esta manera infectar el tubérculo.

Tabla 5. Identificación de la incidencia de las principales enfermedades de tubérculos comerciales de ñame (Dioscorea spp.) durante el momento de la cosecha

\begin{tabular}{ll}
\hline \multicolumn{1}{c}{ Clon } & \multicolumn{1}{c}{ Plagas identificadas } \\
\hline Papa & Botryodiplodia theobromae y Penicillium spp. \\
Caballo & Botryodiplodia theobromae y Penicillium spp. \\
Caraqueño & Penicillium spp. y Aspergillus flavus Link. \\
Chino Blanco & \\
Criollo & Penicillium spp. y Aspergillus flavus Link. \\
\hline
\end{tabular}

En este sentido Dumet y Ogunsola (2008), refieren que la principal enfermedad en la cosecha del cultivo del ñame es la pudrición del tubérculo, la cual es causada por diferentes tipos de hongos. Entre estas podemos encontrar: pudriciones suaves causadas por Penicillium spp., Fusarium oxysporum y Botrydiplodia theobromae; y pudriciones secas causadas por Rosselinia y Sphaerostilbe. Otros hongos encontrados frecuentemente son Rhizopus nodosus y F. solani. 
Las pudriciones en el rizoma del ñame son generadas desde el campo y progresan durante el almacenamiento. Pueden ocurrir: pudriciones secas (que provocan manchas ligeras y debilitamiento de la planta), pudriciones húmedas (que desintegran el tejido en una masa acuosa) y pudriciones fuertes (que provocan maceración total del tejido). Se han determinado varios microorganismos que provocan la pudrición del rizoma (Sclerotium rolfsii, Botryodiplodia theobromae, Penicillium spp., Rhizopus spp., Fusarium spp.) (MINAG, 2008).

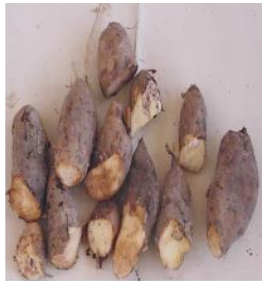

A

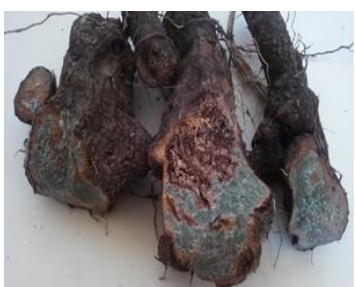

B

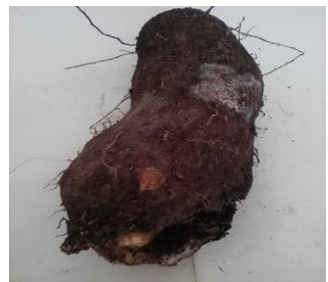

$\mathbf{C}$

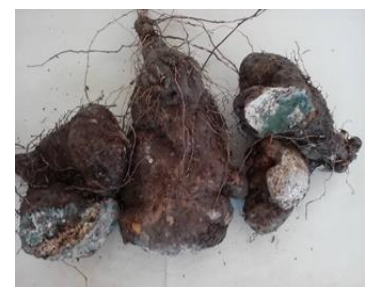

D

Fig.1. Presencia de Botryodiplodia theobromae, Penicillium spp. y Aspergillus flavus Link. en los diferentes clones de ñame (Dioscorea spp.) evaluados: Botryodiplodia theobromae y Penicillium spp. Clon Papa (A) y Clon Caballo (B); Penicillium spp. y Aspergillus flavus Link. Clon Caraqueño (C) y Clon Criollo (D).

Pérdidas superiores (25\%) en estos tipos de almacenamiento tradicional han sido informadas. Estas se deben a diversos factores: el nematodo Scutellonema, comúnmente denominado nematodo del ñame, es uno de los más importantes. Los tubérculos de ñame infestados con esta plaga al momento de la recolección no se conservan. Otro nematodo importante es el nematodo de la raíz, pero éste generalmente no afecta a la conservación; las podredumbres fúngicas y bacterianas son la causa de gran parte de las pérdidas durante el almacenamiento, muchos de ellos son patógenos (FAO, 1985).

\section{Respuesta de tubérculos comerciales de ñame (Dioscorea spp.) durante su almacenamiento poscosecha a temperatura ambiente con luz solar indirecta en un local limpio y ventilado.}

En el almacenamiento poscosecha de los tubérculos comerciales se eliminaron todos los tubérculos enfermos o dañados por los instrumentos de cosecha y se procedió a su almacenamiento en un lugar ventilado, limpio y bajo luz solar indirecta. Este proceder coincidió con lo señalado por MINAG (2008) donde se declara que para realizar un correcto almacenamiento debe tenerse la precaución de eliminar todos los tubérculos enfermos o dañados por los instrumentos de cosecha; debe colocarse a la sombra, aunque siempre se producen pérdidas de peso que en el caso de D. alata puede oscilar entre un 8-23\% dependencia del clon almacenado.

Por otro lado FAO (1985) señala que es muy importante observar la condición de los tubérculos de ñame al momento de almacenarlos, para determinar la duración del almacenamiento. Sólo podrán almacenarse los ñames que estén en buen estado, es decir, los tubérculos exentos de nematodos, de podredumbres y de lesiones físicas. Para reducir las lesiones físicas, es necesario manipular cuidadosamente los tubérculos durante todas las operaciones de recolección y transporte. Toda lesión, raspadura o magulladura o corte profundo producido con el machete o azadón utilizado para excavar predispondrá al tubérculo al ataque de patógenos y a la pudrición posterior durante el almacenamiento. Es importante evitar la exposición de los tubérculos, especialmente los recién excavados, durante largo tiempo, a un sol intenso, ya que ello puede provocar lesiones y favorecer la putrefacción. 


\section{Características morfológicas}

En la tabla 6 se exponen el color de distintos clones de ñame (Dioscorea spp.) a los 0, 30 y 60 a temperatura ambiente con luz solar indirecta en un local limpio y ventilado contenido dentro de sacos de aspillera. Se observa variabilidad de color en el rango de castaño oscuro a castaño claro.

Tabla 6. Color de diferentes clones comerciales de ñame (Dioscorea spp.) a los 0,30 y 60 días de almacenamiento a temperatura ambiente con luz solar indirecta en un local limpio y ventilado contenido dentro de sacos de aspillera.

\begin{tabular}{ccccc}
\hline No & Clon & 0 días & 30 días & 60 días \\
\hline 1 & Criollo blanco & Castaño medio & Castaño medio & Castaño claro \\
2 & Caballo & Castaño oscuro & Castaño medio & Castaño medio \\
3 & Caraqueño & Castaño claro & Castaño medio & Castaño medio \\
4 & Chino blanco & Castaño oscuro & Castaño medio & Castaño medio \\
5 & Papa & Castaño claro & Castaño claro & Castaño claro \\
\hline
\end{tabular}

También se aprecia en la tabla 7 disímiles formas de los tubérculos de distintos clones de ñame (Dioscorea spp.) a los 0, 30 y 60 días a temperatura ambiente con luz solar indirecta en un local limpio y ventilado contenido dentro de sacos de aspillera, donde se observa variabilidad de formas.

Tabla 7. Forma de diferentes clones de ñame (Dioscorea spp.) a los 0,30 y 60 días de almacenamiento a temperatura ambiente con luz solar indirecta en un local limpio y ventilado contenido dentro de sacos de aspillera.

\begin{tabular}{ccccc}
\hline No & Clon & 0 días & 30 días & 60 días \\
\hline 1 & Criollo blanco & Oblongo & Oblongo & Oblongo \\
2 & Caballo & Alargado achatado & Alargado achatado & Alargado achatado \\
3 & Caraqueño & Irregular & Irregular & Irregular \\
4 & Chino blanco & Ovado & Ovado & Ovado \\
5 & Papa & Elíptica & Elíptica & Irregular \\
\hline
\end{tabular}

Jiménez y Hernández (2009) refieren que la descripción morfológica de órganos vegetativos y reproductivos y rasgos agronómicos clásicos han sido de gran utilidad para la caracterización y evaluación de recursos genéticos. Estos descriptores pueden ser definidos como atributos observables de la planta, y fácilmente cuantificables e identificables; que permiten una discriminación rápida de fenotipos.

Estos resultados son comparables con los descritos por Leyva (2017) al evaluar desde el punto de vista morfoagronómico el banco de semilla categorizada de ñame ubicado en las áreas del Centro de Estudios de Biotecnología vegetal de la Universidad de Granma. También corresponden con los de Aguilar (2012) al caracterizar morfológica y molecularmente la colección de Dioscorea spp. del Banco de Germoplasma del Centro Agronómico Tropical de Investigación y Enseñanza (CATIE), Costa Rica.

Por otra parte, Orhevba et al. (2006) señalaron que las características de almacenamiento son diferentes para las distintas especies de ñames. Como regla general, el ñame de agua (Dioscorea alata) se conserva mejor que el ñame blanco (D. rotundata), y éste mejor que el ñame amarillo (D. cayenensis). Hay también diferencias entre variedades de la misma especie. Clones que presentan mejores características de almacenamiento con un período de latencia más prolongado, las que cicatrizan bien y las que tienen formas que facilitan la excavación sin lesiones. Los clones que tienen malas características de almacenamiento deberían consumirse o venderse en primer lugar, y conservarse sólo los clones que tienen buenas características de almacenamiento. 


\section{Masa fresca de los tubérculos}

En la tabla 8 se muestra la masa fresca de tubérculos (MFT) de diferentes clones de ñame (Dioscorea spp.) en distintos momentos de almacenamiento, donde se aprecia que a los 0 días se encuentra en un rango de 1.1 a $0.10 \mathrm{~kg}$ con un valor promedio de $0.66 \mathrm{~kg}$. Los mayores valores significativos $(\mathrm{p}<0.05)$ se presentaron en los clones, Caballo, Chino blanco y Caraqueño $(1.1,0,90$ y $0.66 \mathrm{~kg})$, seguido de los clones Criollo y Papa (0.45 y $0.10 \mathrm{~kg}$ ). A los 30 días se encuentra en un rango de 0,82 a $0.08 \mathrm{~kg}$, con un valor promedio de $0.52 \mathrm{~kg}$; destacándose los clones Chino blanco, Caballo y Caraqueño $(0.82,0.72$ y $0,52 \mathrm{~kg})$, seguido de los clones Criollo y Papa $(0.43,0.08 \mathrm{~kg})$. A los 60 días de almacenamiento se encontraba en un rango de $0.80 \mathrm{a} 0.07 \mathrm{~kg}$, con un valor promedio de $0.47 \mathrm{~kg}$, destacándose nuevamente los clones Chino Blanco, Caballo y Caraqueño $(0.80,0.70$ y $0.47 \mathrm{~kg})$.

Tabla 8. Masa fresca de tubérculos (kg) de diferentes clones comerciales de ñame (Dioscorea spp.) en distintos momentos de almacenamiento a temperatura ambiente con luz solar indirecta en un local limpio y ventilado contenido dentro de sacos de aspillera.

\begin{tabular}{cccccc}
\hline Tratamientos & Criollo Blanco & Chino Blanco & Caballo & Caraqueño & Papa \\
\hline 0 días & $0,45 \mathrm{~d}$ & $0,90 \mathrm{~b}$ & $1.1 \mathrm{a}$ & $0,66 \mathrm{c}$ & $0,10 \mathrm{e}$ \\
30 días & $0,43 \mathrm{~d}$ & $0,82 \mathrm{~b}$ & $0,72 \mathrm{a}$ & $0,52 \mathrm{c}$ & $0,08 \mathrm{e}$ \\
& $0,42 \mathrm{~d}$ & $0,80 \mathrm{~b}$ & $0,70 \mathrm{a}$ & $0,47 \mathrm{c}$ & $0,07 \mathrm{e}$ \\
\hline 0 días & 0,04 & 0,03 & 0,13 & 0,05 & 0,008 \\
\hline
\end{tabular}

Medias con letras distintas difieren significativamente para p <0.05 según prueba de Tukey. EE, error estándar.

Se evidenció en todos los clones analizados que a medida que pasa el tiempo de almacenamiento disminuyó la masa fresca de tubérculo, lo que puede deberse a una pérdida de agua durante este período que osciló entre 18 y 26\%. Estos resultados se corroboran con los obtenidos por Osunde (2003) al evaluar distintos clones de ñame de la especie $D$. alata donde la pérdida de masa fresca oscilo en un rango de 19 a $22 \%$. Resultados similares para la pérdida de masa fresca en D. alata han sido informados por MINAG (2008) en un rango de $8-23 \%$ en dependencia del clon almacenado.

\section{Masa seca de tubérculos}

El contenido de masa seca (\%) de diferentes clones de ñame (Dioscorea spp.) en distintos momentos de almacenamiento se expone en la tabla 9, donde se aprecia que a los 0 días se encuentra en un rango de 29 a $22 \%$. Alcanzando los mayores porcentajes significativos $(\mathrm{p}<0.05)$ los clones Caballo y Papa $(29$ у $25 \%)$ seguido del resto. A los 30 días se encuentra en un rango de 30 a $23 \%$ alcanzando los mayores porcentajes significativos en los clones Caballo y Papa (30 y 27\%) seguido del resto de los clones. A los 60 días como es evidente se encuentra en un rango de 31 a $24 \%$ alcanzando los mayores porcentajes significativos en los clones Caballo, Papa y Chino Blanco (31, 28 y 25\%), seguido de los clones Caraqueño y Criollo (24\%).

Tabla 9. Contenido de masa seca (\%) de tubérculos de diferentes clones de ñame (Dioscorea spp.) en distintos momentos de almacenamiento a temperatura ambiente con luz solar indirecta en un local limpio y ventilado contenido dentro de sacos de aspillera.

\begin{tabular}{cccccc}
\hline Tratamientos & Criollo Blanco & Chino Blanco & Caballo & Caraqueño & Papa \\
\hline 0 días & $22 \mathrm{c}$ & $23.3 \mathrm{c}$ & $29 \mathrm{a}$ & $22.3 \mathrm{c}$ & $25 \mathrm{~b}$ \\
30 días & $23 \mathrm{c}$ & $24 \mathrm{c}$ & $30 \mathrm{a}$ & $23 \mathrm{c}$ & $27 \mathrm{~b}$ \\
60 días & $24 \mathrm{c}$ & $25 \mathrm{c}$ & $31 \mathrm{a}$ & $24 \mathrm{c}$ & $28 \mathrm{~b}$ \\
\hline EE & 0,5 & 0,5 & 0,5 & 0,5 & 0,8 \\
\hline
\end{tabular}

Medias con letras distintas difieren significativamente para $\mathrm{p}<0.05$ según prueba de Tukey. EE, error estándar.

En resumen se observó que a menor masa fresca de los tubérculos hay un mayor contenido de materia seca lo cual se debe a la pérdida de agua por transpiración durante el almacenamiento de los tubérculos, lo que puede 
influir en la calidad de los mismos. Estos resultados son comparables a los obtenidos por Lebot et al. (2009) durante la caracterización físico-química de tubérculos de ñame (Dioscorea spp.) los cuales lograron un contenido de materia seca un rango de 13.68 a $37.4 \%$.

\section{Porcentaje de brotación}

El porcentaje de brotación a los 60 días, arrojó los mayores valores significativos $(\mathrm{p}<0.05)$ en los clones Papa y Chino blanco con un 80 y 76\% de brotación, seguido de los clones Caraqueño (63.3\%) y Criollo (53.3\%). Estos resultados son similares a los alcanzados por Leyva (2017) a los 30 días de establecidas las plantas en condiciones de campo donde alcanzó porcentajes de brotación en los tratamientos de la especie $D$. alata, clon Caraqueño $82.00 \%$; y clon Chino Blanco $87.5 \%$. Sin embargo, no coinciden con los valores superiores alcanzados para el clon Criollo $87.4 \%$, clon Caballo $99.00 \%$ y D. esculenta clon ñame Papa (38\%).

\section{Diámetro y longitud del brote}

Los resultados del diámetro y la longitud del brote se exponen en la tabla 11, donde el mayor resultado lo mostró el clon Chino Blanco con un diámetro de $0.76 \mathrm{~cm}$ y una longitud de $14.82 \mathrm{~cm}$, siendo los menores resultados del clon Papa con un diámetro de $0.42 \mathrm{~cm}$ y longitud de $1.28 \mathrm{~cm}$. Estos resultados concuerdan con los obtenidos por Viola et al. (2007) al evaluar el efecto de 3 inhibidores de brotación en papa criolla (Solanum phureja) variedad criolla aplicados en el proceso de poscosecha donde obtuvieron como mínimo 2 $\mathrm{mm}$ de longitud y $1 \mathrm{~mm}$ de diámetro.

Tabla 11. Diámetro y longitud del brote de diferentes clones comerciales de ñame (Dioscorea spp.) a los 60 días de almacenamiento con luz solar indirecta en un local limpio y ventilado contenido dentro de sacos de aspillera.

\begin{tabular}{ccc}
\hline Clones & DB $(\mathrm{cm})$ & LB $(\mathrm{cm})$ \\
\hline Criollo & $0.58 \mathrm{~b}$ & $1 \mathrm{~d}$ \\
Caballo & $0 \mathrm{e}$ & $0 \mathrm{e}$ \\
Caraqueño & $0.55 \mathrm{c}$ & $3.40 \mathrm{~b}$ \\
Chino Blanco & $0.76 \mathrm{a}$ & $14.82 \mathrm{a}$ \\
Papa & $0.42 \mathrm{~d}$ & $1.28 \mathrm{c}$ \\
\hline EE & 0.03 & 1.43
\end{tabular}

Medias con letras distintas difieren significativamente para $\mathrm{p}<0.05$ según prueba de Tukey. EE, error estándar.

Resultados similares alcanzados por Leyva (2017) en el diámetro de los clones Criollo y Caraqueño (0.60; 0.61) y mucho menor para el clon Papa $(0.14 \mathrm{~cm})$. La diferencia mostrada por el clon Papa obedece a la característica de la especie cuya arquitectura presenta tallos muy delgados.

\section{Identificación de las principales plagas y enfermedades}

Durante el almacenamiento poscosecha de tubérculos comerciales de ñame (Dioscorea spp.) a temperatura ambiente no se detectó incidencia de plagas y enfermedades hasta 60 días lo que demuestra que el método de almacenamiento resultó apropiado para el mantenimiento de los indicadores de calidad de los tubérculos comerciales de ñame.

\section{Pruebas organolépticas}

Los resultados de las pruebas organolépticas de tubérculos de diferentes clones comerciales de ñame (Dioscorea spp.) a 0 y 60 días para la evaluación del sabor y aspecto de tubérculos hervidos de diferentes clones de ñame (Dioscorea spp.) arrojaron los mejores resultados al clon Caraqueño a los 0 días con un 90\% de excelente y un $10 \%$ de bueno, seguido en orden de categoría evaluativa los clones Chino Blanco, Criollo y Papa con un $70 \%$ de excelente, luego Caraqueño con $70 \%$ de bueno y por último el Caballo con $90 \%$ de regular. Sin embargo a los 60 días los panelistas escogieron el clon Chino Blanco con un 70\% de excelente, seguido del Papa (50\%), Caraqueño y Criollo (40\%), y por último el Caballo con un 40\%. Resultados semejantes alcanzó Hidalgo (2014) al caracterizar la calidad nutricional de tubérculos de ñame (Dioscorea spp.) a través de diferentes técnicas de análisis, donde los valores superiores correspondieron al clon Chino blanco con un $70 \%$ de excelente y un $30 \%$ de bueno, seguido por los clones Criollo y Papa con $80 \%$ y $60 \%$ de bueno respectivamente. 
Los resultados correspondientes a la textura de tubérculos hervidos de diferentes clones de ñame (Dioscorea spp.) evidenciaron a los 0 y 60 días que, el clon Chino Blanco posee la mejor textura (blanda) lo que fue declarado por el $100 \%$ de los encuestados, seguido por el clon Papa (80\%), Caballo (30\%) y Criollo (20\%) en esta categoría y en la textura blanda le sigue los clones Caraqueño (100\%), Criollo (80\%) y Caballo (70\%). Resultados comparables fueron descritos por Hidalgo (2014), donde el clon Chino Blanco demostró una textura de $100 \%$ blanda, seguido por los clones Caballo y Criollo en la textura semidura (100\%), sin embargo el clon Caraqueño alcanzo un $80 \%$ pero en la categoría de blanda.

De igual modo el deseo de los panelistas de volver a consumir tubérculos hervidos de diferentes clones de ñame (Dioscorea spp.), mostró a los 0 y 60 días el clon Chino Blanco el más aceptado donde el 100\% desea consumirlo siempre, seguido en orden por los clones Papa, Caraqueño y Criollo con un $80 \%$, por ultimo aparece el clon Caballo donde el $80 \%$ de los panelista nunca desea consumirlo.

En este aspecto Poot-Matu et al. (2000) refiere que los tubérculos se consumen cocidos, en puré, en sopas y guisos. Se consume frito, forma en la que se preparan hojuelas crocantes. También se prepara una chicha o "masato" de ñame. En África, el ñame se usa en la preparación de "fufú" alimento tradicional en estos pueblos, que consiste en una masa elástica elaborada con ñame cocido, molido y amasado en un mortero de madera.

Por otra partes el ñame (Dioscorea spp.) es un cultivo de gran importancia para la seguridad alimentaria ya que posee excelentes características nutricionales y gran adaptabilidad a diferentes condiciones edafoclimáticas, lo cual contribuye a su productividad (Borges et al., 2016).

Reducción de pérdidas mediante el manejo de tubérculos de Dioscorea spp. durante su cosecha y almacenamiento poscosecha.

A continuación se describen un conjunto de medidas de manejo del cultivo que fueron consideras como esenciales para reducir las pérdidas durante la cosecha y almacenamiento de los tubérculos comerciales.

- Efectuar la plantación en canteros de $50 \mathrm{~cm}$ de altura $(0,5 \times 1 \mathrm{~m})$ para de esta manera evitar o reducir posibles daños mecánicos durante el momento de la cosecha.

- Realizar la cosecha entre los 8 y 9 meses.

- Si en el momento del muestreo durante la cosecha el ápice es de color claro, se puede dejar reposando en el suelo un tiempo prudencial ( 2 a 3 semanas). Si el ápice está oscuro, muy similar al resto del tubérculo, se puede proceder con la cosecha.

- Realizar la cosecha manual utilizando la coa para de esta manera evitar daños mecánicos mayores

- Efectuar el lavado con el fin eliminar los residuos de suelo y de materia orgánica que permanecen adheridos a los tubérculos.

- Almacenar los tubérculos colgados en sacos de aspillera en un local, limpio, ventilado, a temperatura ambiente y con iluminación solar indirecta.

- Secar los tubérculos para bajar la humedad externa de los tubérculos y minimizar el ataque de las plagas durante el transporte y el almacenamiento.

\section{Conclusiones}

- Se identificó como principales enfermedades de tubérculos comerciales de ñame durante el momento de cosecha a Botryodiplodia theobromae, Penicillium spp. y Aspergillus flavus, Link.

- Se determinó para todos los clones evaluados que a medida que pasa el tiempo de almacenamiento hasta 60 días disminuye el porcentaje de masa fresca de tubérculo y aumenta el de masa seca.

- Se logró el almacenamiento satisfactorio de los tubérculos comerciales de ñame de D. alata de los clones Criollo, Chino Blanco, Caballo, Caraqueño y de D. esculenta clon Papa en sacos de aspillera hasta 60 días en un local ventilado, limpio y con luz solar indirecta a temperatura ambiente.

- Se elaboró un plan de medidas para el manejo de tubérculos de Dioscorea spp. durante su cosecha y almacenamiento poscosecha. 


\section{Recomendaciones}

- Realizar estudios de almacenamiento en sacos de aspillera hasta 180 días en un local ventilado, limpio y con luz solar indirecta a temperatura ambiente de tubérculos comerciales de ñame de D. alata de los clones Criollo, Chino Blanco, Caballo, Caraqueño y de D. esculenta clon Papa.

\section{Referencias}

Abasimi I. (2018). Determinants of Yam Production and Choice of Market Outlet in Ghana: A Case Study in the Upper West Region. European academic research. Vol. V, Issue 10.

Adejo P.E. (2017). Post-Harvest Management Practices of Yam and Farmers' Information Needs in the North-Central of Nigeria. J Nutraceuticals Food Sci. Vol. 2 No. 3:9.

Akinrinola O.O. \& Adeyemo A.O. (2018). The Impact of Agricultural Technology Adoption on Poverty: The Case of Yam Minisetts Technology in Ekiti State, Nigeria. Journal of Agricultural Research. 3(9): 000195.

Andres C., Adeoluwa O.O. \& Bhullar G.S. (2017). "Yam (Dioscorea spp.)," in Encyclopedia of Applied Plant Sciences, Vol. 3., eds B. Thomas, B. G. Murray, and D. J. Murphy (Waltham, MA: Academic Press),435-441.

Ansah I.G.K. \& Tetth B.K.D. (2016). Determinants of yam postharvest management in the Zabzugu district of northern Ghana. Adv in Agr: 1-9.

Ayado S. (2017). Discordant tunes over yam export policy in Nigeria. Article published in the Leadership Newspaper 19th June 2017.

Borges M., Malaurie B., Meneses S., Gómez R. \& Verdeil J. (2016). Anatomía comparada de plantas de Dioscorea alata L. clon 'Caraqueño' cultivadas en tres ambientes de crecimiento in vitro. Revista Colombiana de Biotecnología 18(2): 112-118.

Claudius-Cole A.O., Kenyon L. \& Coyne D. L. (2017). Effect of pre-plant treatments of yam (Dioscorea rotundata) setts on the production of healthy seed yam, seed yam storage and consecutive ware tuber production. Journal of Agriculture and Rural Development in the Tropics and Subtropics. Vol. 118 No. 2: 297-306.

CMI (Commonwealth Mycological Institute). (1976). Comprehensive index to mycological descriptions, Kew, Surrey, England, 500 pp.

Coursey, D.G. (1967). Yams, an account of the nature, origins, cultivation and utilisation of the useful members of the dioscoreaceae. London, Longmans. Tropical Agriculture Series, $230 \mathrm{pp}$.

Dumet D. \& Ogunsola D. (2008). Guías para la regeneración de germoplasma: ñame. En: Dulloo M.E., Thormann I., Jorge M.A. \& Hanson J., editors. Crop specific regeneration guidelines [CD-ROM]. CGIAR System-wide Genetic Resource Programme (SGRP), Rome, Italy. 8 pp.

FAO. (1985). Prevención de pérdidas de alimentos poscosecha. Manual de capacitación. Roma. Italia. 4pp.

FAO. (2011). Inspección fitosanitaria de plantas y partes de plantas para propagación, multiplicación o ser plantadas. Manual de Inspección Fitosanitaria. Pp. 60-74.

FAO. (2016). El ñame africano, un cultivo tradicional altamente nutritivo pero poco conocido. Boletin Naciones Unidas. 21 octubre.4 pp.

Iddi F.Y., Donkoh S. A., Danso-Abbeam G., Karg H., Akoto-Danso E. K. (2018). Marketing efficiency analysis of yam value chain in the northern region of Ghana. UDS International Journal of Development. Volume 5 No. 1.

Jiménez D. \& Hernández R. (2009). Manual Técnico del Cultivo del ñame. IDIAP. Panamá.44 pp.

Lebot, V. (2009). Tropical root and tuber crops: cassava, sweet potato, yams and aroids. Wallingford: CABI. Crops production Science in Horticultures Series, $17 \mathrm{pp}$.

Leyva H. (2017). Banco de semilla categorizada y mejoramiento de la tecnología del cultivo de ñame (Dioscorea spp.) en la provincia Granma, Tesis de Maestría en Ciencias Agrícolas, Universidad de Granma, pp. 90-92.

Hidalgo M. (2014). Caracterización bioquímica y nutricional de tubérculos de ñame (Dioscorea spp.). Trabajo de Diploma, Universidad de Granma, pp. 49. 
MINAG. 2008. Instructivo Técnico del Cultivo del Name. Castellanos, P. (Ed.). SEDGRI/AGRINFOR, Ciudad de La Habana, Cuba, 18 pp.

Osunde Z. D., Yisa M. G. \& El-Okene A. M. (2003). Quality changes of yam under different storage structures. Proceedings of the Fourth International Conference and 25 th Annual General Meeting of the Nigerian Institution of Agricultural Engineers held at Damaturu 25, 206-212.

Poot-Matu J.E. \& Cortés M.A. (2000). Serie Técnica de raíces y tubérculos No 3, 5 y 6 . Tabasco, México.

Quainoo A. K., Addai I. K., Damba Y. \& Opoku N. (2015). Seed Yam (Dioscorea esculentum) Improvement for Income and Food Security in Northern Ghana. Research in Plant Biology, 5(2): 09-16.

Raphiou M., Siaka K., Kouami N., Nebambi L. \& Bello S. (2019). Effect of the Soil and Sawdust Substrates on the Sprouting Rates of Yam Minissetts Varieties in the Guinea Sudan Zone of Benin. International Invention of Scientific Journal. Volume 03 Issue 01.

Statsoft. (2011). Statistica for Windows. Release 10.0. Statsoft Inc., Tulsa, OK, USA.

Universidad de Costa Rica (UCR). (2016). Laboratorio poscosecha realiza estudio sobre calidad del ñame. Boletín diario del Semanario Universitario. 3 pp.

Viola R., Pelloux J., Van der Ploeg A., Gillespie T., Marquis N., Roberts A.G. \& Hancock R.D. (2007). Symplastic connection is required for bud outgrowth following dormancy in potato (Solanum tuberosum L.) tubers. Plant Cell Environ. 30, 973- 983. 